\title{
Unequal household carbon footprints in China
}

Dominik Wiedenhofer ${ }^{a, *}$, Dabo Guan ${ }^{\mathrm{b}, *}$, Zhu Liu', Jing Meng ${ }^{\mathrm{b}}$, Ning Zhang ${ }^{\mathrm{d}}$, Yi-Ming Wei,* $^{\mathrm{e}}$

a. Institute of Social Ecology (SEC), IFF- Vienna, Alpen-Adria University Klagenfurt, Austria

b. School of International Development, University of East Anglia, Norwich, NR4 7JT, UK;

c. Kennedy School of Government, Harvard University, Cambridge, MA 02138, US.

d. College of Economics, Jinan University, Guangzhou, 510632, China.

e. Center for Energy and Environmental Policy Research, Beijing Institute of Technology, Beijing 100081, China.

*Corresponding email: Dominik.wiedenhofer@aau.at; dabo.guan@uea.ac.uk; wei@bit.edu.cn

Keywords: climate justice; carbon footprint; inequality; sustainable consumption; multi-regional input-output analysis;

Households' carbon footprints are unequally distributed among the rich and poor due to differences in the scale and patterns of consumption. We present distributional focused carbon footprints for Chinese households and use a carbon-footprint-Gini coefficient to quantify inequalities. We find that in 2012 the urban very rich, comprising $4 \%$ of population, induced $19 \%$ of the total carbon footprint from household consumption in China with $6.4 \mathrm{tCO} / \mathrm{cap}$. The average Chinese household footprint remains comparatively low (1.7 tCO2/cap), while those of the rural population and urban poor, comprising $64 \%$ of population, are 0.5 - 1.6 tCO2/cap. Between 2007 and 2012 the total footprint from households increased by $19 \%$, with $75 \%$ of the increase due to growing consumption of the urban middle class and the rich. This suggests that a transformation of Chinese lifestyles away from the current trajectory of carbon-intensive consumption patterns requires policy interventions to improve living standards and encourage sustainable consumption.

The growing climate crisis $^{1}$ shows that becoming wealthy, while enabling a clean-up of the local environment ${ }^{2}$, drives economic activity and subsequently carbon emissions, often in distant places $^{1,3,4}$. The concept of a carbon footprint, is increasingly used in the public debate on responsibility and mitigation of climate change to describes the direct and indirect carbon emissions of consumption along the international supply chain ${ }^{5-8}$. To achieve absolute reductions of emissions fairly, proposals grounded in climate justice have been put forward to target high emitting individuals across all countries ${ }^{9-11}$ while ensuring minimum levels required for a human development ${ }^{11}$. In 2013 a growing global upper class of top $10 \%$ consuming households already contributed $40-51 \%$ of global emissions from fossil fuels and other sources with their footprints, a third of them in emerging economies like $\mathrm{China}^{10}$. At the same time the global poor (lower $50 \%$ of global income distribution)

$$
1 / 16
$$


are driving $10-13 \%$ of global greenhouse gas emissions ${ }^{10}$. Improved methods ${ }^{12}$ as employed in this study provide important information for policy-makers to explicitly consider the interactions and trade-offs between measures targeting inequality, poverty, climate mitigation and towards sustainable lifestyles for the emerging middle class and rich households.

China, which recently announced a stronger focus on bolstering domestic consumption over its current export orientation, is steadily moving towards carbon- and resource intensive consumer lifestyles, tracking the way of high-income countries ${ }^{1,5,8,13,14}$. The sheer scale of the Chinese economy means that the future global climate is strongly determined there ${ }^{1,14,15}$. Since the 1980's a rapid reduction of the proportion of people living below the poverty line of 1.9 dollar (2011 PPP) income per day has been achieved, from $88 \%$ in 1981 to $11 \%$ in $2014^{16}$. At the same time income inequality grew substantially to a Gini-Index of 0.55 in 2010, leading to a stop of official reporting on the Gini coefficient for incomes ${ }^{17}$, an established indicator on income distributions. A clear urban-rural divide of energy consumption can be observed in China, where rural households often use traditional and locally polluting energy carriers like straw, wood or coal while electricity and natural gas is slowly penetrating these areas ${ }^{18,19}$. In urban areas modern energy carriers like electricity, natural gas and LPG are dominant and mobility is the main driver of direct household energy use $\mathrm{e}^{18,19}$. Annually approximately 20 million people move from rural to urban areas and future population growth is projected to be concentrated in cities, which entails large new infrastructure and housing requirements ${ }^{5}$. Especially in urban areas a sizeable middle class and a small segment of households with high incomes has emerged ${ }^{5,8,20}$, while large swaths of rural China and migrant workers coming to cities still largely remain in poverty ${ }^{21}$. Increasing consumption in urbanizing China has been identified as important driver of household carbon footprints over the last 20 years, due to growing urban population and incomes, while decreasing carbon intensity of the Chinese economy only weakly dampens these trends ${ }^{5,22,23}$. These growing disparities in incomes and carbon footprints are driven by government investment policies favouring coastal and urban areas ${ }^{17}$. But in a globally carbonconstrained future with the urgent need for absolute reductions of annual emissions ${ }^{1,24}$, relying on economic growth to lift all boats while also decreasing inequality and improving human development can become very challenging. Clearly decarbonising the energy system via production-focused efficiency measures and energy pricing reforms is essential ${ }^{3,25,26}$. But developing carbon-free lifestyles beyond the current trajectory of increasing carbon footprints while becoming wealthy will require much more substantial debates on the limits of green consumerism and the potentials towards sustainable consumption ${ }^{11,20,27-29}$.

Herein we present the unequal distribution of carbon footprints between Chinese households along national and international supply chains for 13 income groups (5 rural and 8 urban). We quantify 
inequality between urban-rural and 13 income groups with a carbon-footprint-Gini coefficient (CFGini), for the latest available years 2012 and 2007. Gini coefficients are used to quantify inequality ${ }^{10,17,30}$ and were applied to production-based territorial emissions ${ }^{30}$, cumulative historical territorial emissions ${ }^{31}$, interregional assessments of household footprints ${ }^{7}$, urban Chinese carbon footprints $\mathrm{s}^{20}$ and estimates of household carbon footprints across countries ${ }^{10,12}$. For income inequality and carbon footprints an inverse relationship was found ${ }^{32-37}$. We utilize a detailed Chinese InputOutput Table with latest, substantially revised Chinese emissions statistics ${ }^{38,39}$ and a Multi-Regional Input-Output Model (GTAP 9 database) for all other countries. Emissions datasets cover carbon emissions from fossil fuels and cement production.

From a production-based territorial perspective Chinese carbon emissions are 6.7 tons of per capita in $2013^{38}$. But from a consumption-based perspective the majority of Chinese emissions are related to capital investments $(48 \%)$ and exports $(20 \%)$ as main drivers ${ }^{3,23}$, while households only induce $17 \%$ of the national footprint in 2012. We find that the average Chinese household footprint is only 1.7 $\mathrm{tCO}_{2} / \mathrm{cap}$ in 2012, more than double the Indian average (0.9 $\mathrm{tCO}_{2} / \mathrm{cap}$ ), similar to the Brazilian average (1.5 $\left.\mathrm{tCO}_{2} / \mathrm{cap}\right)$, but one quarter of that in the EU27 $\left(6.7 \mathrm{tCO}_{2} / \mathrm{cap}\right)$ and one sixth of that in the USA (10.4 $\mathrm{tCO}_{2}$ /cap) (Fig. 1, Table 1). However, due to high income inequality in China ${ }^{17}, 4 \%$ of the Chinese population, the very rich urban dwellers, have carbon footprints of consumption at 6.4 $\mathrm{tCO}_{2} / \mathrm{cap}$, nearly 4 times of the average Chinese. The three richest urban groups, $18 \%$ of Chinese population, induce $48 \%$ of the total Chinese household carbon footprint. At the same time rural China and the urban poor, $60 \%$ of the population, only induce $31 \%$ of the total household footprint, all below the national average of $1.7 \mathrm{tCO}_{2} /$ cap. The total household carbon footprint of 1,354 million Chinese is estimated at 2,332 Million tons of $\mathrm{CO}_{2}$. In comparison, the total footprint of 1,247 million Indians is only half $\left(1,152 \mathrm{MtCO}_{2}\right)$, while 500 million Europeans, $37 \%$ the population size of China, have 1.4 times the total footprint (EU27: 3,347 $\mathrm{MtCO}_{2}$ ) and 312 million US-Americans, $23 \%$ the population of China, also have 1.4 times the total carbon footprint $\left(3,262 \mathrm{MtCO}_{2}\right)($ Table 1$)$.

\section{FIGURE 1 GOES HERE}

Figure 1: Carbon footprints of Chinese and international household consumption in 2012/11, from fossil fuels and cement production. * Due to data constraints the emissions from direct energy use of international households could not be allocated to the respective indirect emissions from mobility and housing. For Chinese households mobility and housing includes direct and indirect emissions.

Urban residents, $47 \%$ of the Chinese population, induce $75 \%$ of the national household carbon footprint in 2012. Their average per capita footprint is $2.4 \mathrm{tCO}_{2}$ (Table 1). The top $4 \%$ very rich urban Chinese spend 7,237 US\$ per year and have a per capita footprint of $6.4 \mathrm{tCO}_{2}$ - which is very similar to the national averages of OECD countries, i.e. Japan ( $6.6 \mathrm{tCO}_{2}$ with 27,692 US\$), Russia ( $5.9 \mathrm{tCO}_{2}$ and 7,585 US\$), the EU27 average (6.7 tCO ${ }_{2}$ and 21,082 US\$) and Germany $\left(7.6 \mathrm{tCO}_{2}\right.$ with 20,374 
US\$) (Figure 1; Table 1). This richest urban group comprises approximately 59 million people or $4 \%$ of the entire Chinese population, inducing 19\% of the total household carbon footprint in 2012 (Table 1). The total footprint of that richest group amounts to $455 \mathrm{MtCO}_{2}, 1.6$ times the entire Brazilian household footprint $\left(290 \mathrm{MtCO}_{2}\right)$. The second group, the urban rich, $4 \%$ of total Chinese population, spends approximately 4,298 US\$ per capita and has an average footprint of $3.7 \mathrm{tCO}_{2}$. The urban middle class, divided into three income groups, spends 1,725-3,159 US\$ and has a per capita footprint of $1.5-2.8 \mathrm{tCO}_{2}$. In total the two urban rich groups and middle class together induce $69 \%$ of the national Chinese household carbon footprint. At the same time the urban poor, divided into three groups totalling $8 \%$ of Chinese population, spend only $650-1,270$ US\$ and have footprints of $0.6-1.1 \mathrm{tCO}_{2} / \mathrm{cap}$. This means their carbon footprints are below the Chinese $\left(1.7 \mathrm{tCO}_{2}\right)$ and Brazilian average $\left(1.5 \mathrm{tCO}_{2}\right)$ but similar to the Indian average $\left(0.9 \mathrm{tCO}_{2}\right)$ and in the same range as Chinese rural households. The extremely poor in urban areas only have a footprint of $0.5 \mathrm{tCO}_{2} / \mathrm{cap}$.

Consumption of Chinese rural households, $53 \%$ of the population, induces $25 \%$ of the national household carbon footprint in 2012 (Table 1). The average rural carbon footprint is $0.9 \mathrm{tCO}_{2} / \mathrm{cap}_{1} 1 / 4$ of the urban average. Further decomposing the rural population into five income groups yields footprints of $0.5-1.6 \mathrm{tCO}_{2} / \mathrm{cap}$. Even the richest rural households, $11 \%$ of the Chinese population, only spend 1,611 US\$ per capita and have a footprint of $1.6 \mathrm{tCO}_{2} / \mathrm{cap}$, which is similar to the urban lower-middle class (1.5 $\left.\mathrm{tCO}_{2} / \mathrm{cap}\right)$. The rural middle and middle-high classes have footprints of 0.8 $1.1 \mathrm{tCO}_{2} / \mathrm{cap}$, spending $785-1,054$ US\$ per capita. The two poorest rural groups, $22 \%$ of the entire Chinese population, have footprints of $0.5-0.6 \mathrm{tCO}_{2}$, which together is only $6 \%$ of the total national household carbon footprint and less than the Indian average footprint.

\section{TABLE 1 GOES HERE}

Table 1: Household carbon footprints from fossil fuels combustion and cement production, population size and final demand across income groups in China for 2012 and 2007 and for international comparisons for 2011. CF elasticities were calculated using the basic income elasticity approach, where the relative change of each income groups $\mathrm{CF} / \mathrm{cap}$ from the average $\mathrm{CF} / \mathrm{cap}$ is divided by the relative change of each income groups expenditure/cap from the average exp/cap in 2012 (for details see method section and SI; US\$ at 2011/2012 MER).

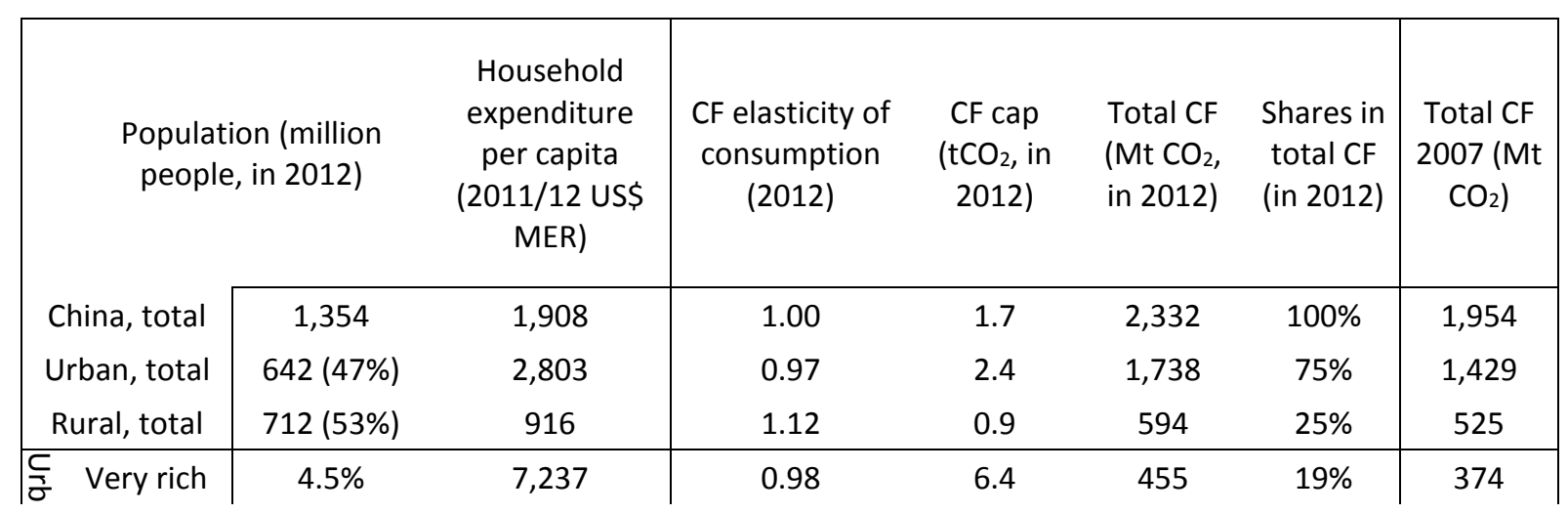




\begin{tabular}{|c|c|c|c|c|c|c|c|c|}
\hline & Rich & $4 \%$ & 4,298 & 0.97 & 3.7 & 266 & $11 \%$ & 220 \\
\hline & $\begin{array}{l}\text { Middle- } \\
\text { high }\end{array}$ & $9 \%$ & 3,159 & 0.97 & 2.8 & 392 & $17 \%$ & 322 \\
\hline & Middle & $9 \%$ & 2,334 & 0.95 & 2.0 & 285 & $12 \%$ & 236 \\
\hline & $\begin{array}{l}\text { Lower- } \\
\text { middle }\end{array}$ & $9 \%$ & 1,725 & 0.96 & 1.5 & 212 & $9 \%$ & 175 \\
\hline & Poor & $4 \%$ & 1,270 & 0.98 & 1.1 & 80 & $3 \%$ & 65 \\
\hline & $\begin{array}{l}\text { Very } \\
\text { poor }\end{array}$ & $2 \%$ & 838 & 1.00 & 0.8 & 27 & $1 \%$ & 21 \\
\hline & $\begin{array}{l}\text { Extremel } \\
\text { y poor }\end{array}$ & $2 \%$ & 650 & 1.00 & 0.6 & 21 & $1 \%$ & 17 \\
\hline & Highest & $11 \%$ & 1,611 & 1.13 & 1.6 & 210 & $9 \%$ & 185 \\
\hline D & $\begin{array}{l}\text { middle- } \\
\text { high }\end{array}$ & $11 \%$ & 1,054 & 1.13 & 1.1 & 138 & $6 \%$ & 117 \\
\hline$\frac{0}{\frac{0}{3}}$ & middle & $11 \%$ & 785 & 1.13 & 0.8 & 102 & $4 \%$ & 92 \\
\hline$\vec{\alpha}$ & Poor & $11 \%$ & 625 & 1.10 & 0.6 & 80 & $3 \%$ & 73 \\
\hline & $\begin{array}{l}\text { Extremel } \\
\text { y poor }\end{array}$ & $11 \%$ & 506 & 1.11 & 0.5 & 65 & $3 \%$ & 58 \\
\hline & India & 1,247 & 939 & & 0.9 & 1,152 & & \\
\hline & Brazil & 193 & 7,707 & & 1.5 & 290 & & \\
\hline$\Xi$ & Russia & 143 & 6,585 & & 5.9 & 845 & & \\
\hline$\frac{0}{3}$ & Japan & 127 & 27,692 & & 6.6 & 843 & & \\
\hline 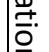 & UK & 63 & 26,479 & & 5.7 & 361 & & \\
\hline$\underline{\underline{D}}$ & Germany & 80 & 26,169 & & 6.4 & 511 & & \\
\hline & EU27 & 500 & 21,082 & & 6.7 & 3,347 & & \\
\hline & USA & 312 & 34,853 & & 10.4 & 3,262 & & \\
\hline
\end{tabular}

Between 2007 and 2012, the total Chinese household carbon footprint increased by $19 \%$ or 378 $\mathrm{MtCO}_{2}, 82 \%$ of these increases due urban consumption (Table 1). The urban 'very rich', $4 \%$ of population, took $21 \%$ of the total increase, more than the increase for all of rural China with $53 \%$ of the population ( 80 vs $70 \mathrm{MtCO}_{2}$ ). Per capita footprints in urban areas increased on average by $2 \%$ from a relatively higher level, while those in rural areas increased by $28 \%$. The poor in urban and rural areas, together $31 \%$ of population, increased their footprint by $16 \%$, but only induced $10 \%$ of the increase in total household footprint. The two richest urban and one rural richest groups together, $20 \%$ of population, increased their footprints by $20 \%$, thereby taking $40 \%$ of the total increase. The urban middle-class induced $41 \%$ of the total increase.

Interestingly for the carbon footprint elasticities of consumption we find slightly elastic relationships for the middle class and richer urban income groups $(0.97-0.98)$, while for the urban poor and rural groups we find proportional to inelastic relationships $(1-1.13)$ (Table 1). For the urban very rich a 
$1 \%$ increase in expenditure would lead to $+0.98 \%$ in carbon footprints, while $+1 \%$ increase of expenditures of the rural poor would lead to $+1.11 \%$. This means that coming out of poverty is relatively carbon intensive, due to low-quality commercial energy such as coal, first purchases of appliances and so forth. Richer households tend to use growing incomes for higher quality commercial energy (electricity, LPG, natural gas) and especially more goods and services, which are relatively less carbon-intensive. When comparing elasticities for 2007 and 2012, interestingly rural households become slightly more carbon intensive, while for urban households the carbon footprint elasticity decreased (see SI).These patterns replicate across countries ${ }^{7,8,19,40}$, where generally with rising affluence the marginal carbon intensity of consumption decreases, but larger overall expenditure still means higher total carbon footprints than less affluent households.

When looking at the contribution of each income group's consumption pattern to the total Chinese footprint, it becomes evident that the urban rich and middle class are driving the categories mobility, goods, and services, while footprints from food and housing are less unequal (Figure 2). For example, $78 \%$ of the total footprint of mobility, $74 \%$ for goods and $75 \%$ for services is due to the urban middle class and the two rich groups, although these income groups only constitute $35 \%$ of the population. At the same time the urban and rural poor together, which also amount to $31 \%$ population only induce $7 \%$ of the mobility related emissions and $10 \%$ of the total Chinese carbon footprints from goods as well as from services.

FIGURE 2 GOES HERE (Single column size?)

Figure 2: Relative distribution of household carbon footprints from fossil fuels and cement, income and population size among 13 income groups in 2012.

Finally we quantify inequality between carbon footprints of Chinese income groups using Lorenz curves and carbon-footprint-Gini Indices. In a Lorenz curve the cumulative share of population is plotted against their cumulative footprints, where the Gini Index then quantifies the area under that curve. We find that CF-Ginis for total and goods footprints are similarly unequally distributed as household expenditure in 2012 (around 0.4) (Fig. 3a). We find higher inequality for carbon footprints of services (0.5) and mobility (0.6), while those for food and housing (0.3) are more equally distributed among the Chinese population. Between 2007 and 2012, national inequality decreased slightly across all categories (Fig. 3b), except for rural food and housing related carbon footprints, which is also the major contributor to increasing per capita footprints in rural areas (Fig 3). While urban inequality did not change significantly (Fig. 3b,c), rural inequality increased (Fig. 3b,d).

Figure 3: Quantifying Inequality - Carbon-footprint-Gini coefficients for 13 Chinese income groups in 2012 and 2007, for carbon emissions from fossil fuels and cement production. 
To encourage economic growth, China's government has enacted policies focusing on increased domestic consumption as a substitute for its declining growth in investment and exports, while also announcing an absolute emissions peak for 2030. Recently Chinese emissions growth did slow down ${ }^{38}$, largely driven by a stabilisation of coal use $\mathrm{e}^{13,39}$. Substantial policy efforts in carbon taxation, feed in tariffs for renewables and accelerated deployment of renewables and nuclear have been modelled to achieve this stabilization of Chinese emissions at modest costs until $2030^{26}$, while most of these current Chinese climate policies consider only regional inequality by using differentiated goals between provinces. But at the same time it is clear that stabilizing the climate at $1.5-2^{\circ} \mathrm{C}$ will require unprecedented absolute global reductions of emissions over the next 2-3 decades ${ }^{1,15}$.

The slight decreases in expenditure inequality between Chinese households, mostly due to a small catch-up of rural households is triggered by governmental subsidies to rural households' general purchase and income tax free policies. But our findings suggest that coming out of poverty is quite carbon-intensive due to a larger carbon-footprint elasticity of consumption of the poorer income groups, strongly driven by their dirtier direct energy mix. But much more problematic are growing carbon footprints of the urban middle-class and the rich, which together induce $69 \%$ of the total Chinese household footprint and rapidly westernise their lifestyles. It has been suggested that income redistribution in urban China could reduce aggregate carbon footprints while improving living standards and income inequality ${ }^{20}$. From the results in Table 1 we can estimate that simply redistributing expenditure to achieve equality at $1,762 \$ / \mathrm{cap}$, which is $-8 \%$ lower than the current average expenditure, would result in a $-1 \%$ decrease of total household footprints, due to differential CF-elasticities. Therefore, social and redistributive policies need to be understood as interacting with climate and energy policy and with efforts towards enabling sustainable lifestyles for all ${ }^{17,20,32,37}$.

While Chinese government is making effort to build regional inequalities into climate policies from production efficiency and technology level approaches (e.g. rich coastal versus poorer inland areas), this study reveals that there are substantial inequalities within these regions and along income groups. The CF-Gini could be useful for developing sustainable consumption programs for those income groups which dominate the footprints of certain consumption areas, or for guiding policy design in achieving poverty alleviation while reducing emissions and increasing energy efficiency. Direct emissions from heating with coal or natural gas currently amount to $11 \%$ of the total footprint and $21 \%$ of the rural footprint. Some practical policies are designed to alleviate poverty and reduce emission at same time. For example, Beijing municipality government set up a subsidisation plan to implement a 'coal replacement by clean energy programme' for every rural households in $\mathbf{4 0 0}$ villages surrounding Beijing. By end of 2017, appropriately 4 million tonnes of coal consumption for residential usage will be saved, which is equivalent to 7 million tonnes of $\mathrm{CO}_{2}$ emissions and 210 
thousand tonnes of $\mathrm{SO}_{2}$. The emission reduction effort is same to three years aggregated emission discharge by 66 thousand taxis in Beijing.

Usually shifting consumer choices is seen as yielding substantial climate mitigation benefits, for example eating less (red) meat and more vegetarian diets, less to no fossil fuelled mobility, energyefficient dwellings and purchasing high(er) quality long-lived goods ${ }^{41,42}$. Tapping these potentials requires substantial policy guidelines, careful policy designs and matching infrastructures. Currently direct mobility emissions from fuels make up only $3 \%$ of the total household footprint, most of it by the rich and urban middle class. But following 'on the road' American culture, there are increasingly demands for cheap $4 \times 4$ fleets by Chinese middle class. Domestic car manufacturers are upgrading production lines to fulfil such demand. Beijing and Shanghai have implemented tailored policy to limit absolute gasoline fleets and encourage electric vehicles (EVs) purchases with heavy subsidies. However such policy ignores China's coal dominating energy mix. China's gasoline vehicle replacement programme with EVs is currently not effective. In fact, evidence shows that the $\mathrm{CO}_{2}$ emissions reduction in the petroleum sector is offset by the increase in $\mathrm{CO}_{2}$ emissions in the electricity sector ${ }^{43}$. The EV programme can be only effective with significant changes in Chinese energy mix towards renewables. Therefore, green consumerism alone (even with policy guidelines) cannot drive the entire production system towards sustainability and more systemic approaches are necessary to achieve sustainable consumption and production ${ }^{11,44,45}$. More sustainable urban forms and spatial planning have been identified as important long-term factor towards facilitating lowcarbon lifestyles, especially in growing cities which are currently expanding their infrastructures $s^{5,6,46,47}$.

Overall the required long-term transformations towards a net-zero carbon society should be included into a national discourse about the currently dominant mode of ecological modernization, green growth and conspicuous consumer lifestyles ${ }^{44}$. The carbon-intensive lifestyles of the wealthy are being emulated and serve as role-models, while investments in infrastructure and cities are made. Based on the CF elasticties (Table 1), a hypothetical scenario of an expenditure catch-up of all Chinese households to the average urban rich expenditure pattern (i.e. mobility by cars and planes and living an average $90 \mathrm{~m}^{2}$ per household) can be estimated, resulting in a tripling of the total Chinese household carbon footprint. A catch-up only to the average urban middle class would translate into a $58 \%$ increase of the total footprint. But in a carbon-constrained post-Paris COP21 future high wellbeing and human development needs to be achieved while rapidly reducing total emissions ${ }^{1,13}$. Reducing inequalities but preventing emission intensive lifestyle westernations in populous developing countries can be a step forward to contribute global climate change mitigation. Cost-effectively using limited public and private funding for these societal goals will be crucial. Some 
countries already achieved a high level of human development (HDI of $>0.8$ ) with an average carbon footprint of 1 ton per capita ${ }^{48-50}$, highlighting that pathways to livable and potentially more sustainable societies exist.

\section{Acknowledgements}

This work was supported by National Key R\&D Program of China (2016YFA0602603 and 2016YFA0602604), the National Natural Science Foundation of China (41629501, 71521002), Austrian National Science funded project "MISO - modelling the global metabolic transition" (P27590), the UK Economic and Social Research Council funded project "Dynamics of Green Growth in European and Chinese Cities" (ES/L016028/1), the UK Natural Environment Research Council funded project "Integrated assessment of the emission-health-socioeconomics nexus and air pollution mitigation solutions and interventions in Beijing (NE/N00714X/1) Many thanks go to Jan Minx, Fridolin Krausmann and Julia K. Steinberger for their feedback on the manuscript, to Glen Peters for support with the global emissions dataset for the GTAP-MRIO and to Prof Liu Yu for his feedback on the concordances to bridge the GTAP-MRIO and the Chinese national IOTs classifications.

\section{Supplementary Materials}

See additional file

\section{Author contributions}

D.W. and D.G. designed the research, performed calculations and discussed the results. D.W. wrote the paper. D.G., Z.L., J.M. and B.W. collected data and contributed to writing the paper.

\section{References}

1. Friedlingstein, P. et al. Persistent growth of $\mathrm{CO} 2$ emissions and implications for reaching climate targets. Nat. Geosci. 7, 709-715 (2014).

2. Carson, R. T. The Environmental Kuznets Curve: Seeking Empirical Regularity and Theoretical Structure. Rev. Environ. Econ. Policy 4, 3-23 (2010).

3. Liu, Z. et al. Targeted opportunities to address the climate-trade dilemma in China. Nat. Clim. Change 6, 201-206 (2015).

4. Hoekstra, A. Y. \& Wiedmann, T. O. Humanity's unsustainable environmental footprint. Science 344, 1114-1117 (2014). 
5. Feng, K. \& Hubacek, K. Carbon implications of China's urbanization. Energy Ecol. Environ. 1, 3944 (2016).

6. Ottelin, J., Heinonen, J. \& Junnila, S. New Energy Efficient Housing Has Reduced Carbon Footprints in Outer but Not in Inner Urban Areas. Environ. Sci. Technol. 49, 9574-9583 (2015).

7. Wiedenhofer, D., Lenzen, M. \& Steinberger, J. K. Energy requirements of consumption: Urban form, climatic and socio-economic factors, rebounds and their policy implications. Energy Policy 63, 696-707 (2013).

8. Liu, L.-C., Wu, G., Wang, J.-N. \& Wei, Y.-M. China's carbon emissions from urban and rural households during 1992-2007. J. Clean. Prod. 19, 1754-1762 (2011).

9. Chakravarty, S. et al. Sharing global $\mathrm{CO} 2$ emission reductions among one billion high emitters. Proc. Natl. Acad. Sci. 106, 11884-11888 (2009).

10. Chancel, L. \& Piketty, T. Carbon and inequality: from Kyoto to Paris. Trends in global inequality of carbon emissions (1998-2013) \& prospects for an equitable adaptation fund. (2015).

11. Di Giulio, A. \& Fuchs, D. Sustainable Consumption Corridors: Concept, Objections, and Responses. GAIA - Ecol. Perspect. Sci. Soc. 23, 184-192 (2014).

12. Grubler, A. \& Pachauri, S. Problems with burden-sharing proposal among one billion high emitters. Proc. Natl. Acad. Sci. 106, E122-E123 (2009).

13. Jackson, R. B. et al. Reaching peak emissions. Nat. Clim. Change 6, 7-10 (2015).

14. Spangenberg, J. China in the anthropocene: Culprit, victim or last best hope for a global ecological civilisation? BioRisk 9, 1-37 (2014).

15. Peters, G. P., Andrew, R. M., Solomon, S. \& Friedlingstein, P. Measuring a fair and ambitious climate agreement using cumulative emissions. Environ. Res. Lett. 10, 105004 (2015).

16. World Bank. World Development Indicators (WDI) Database. (2016). at <data.worldbank.org/indicator>. (2016).

17. Xie, Y. \& Zhou, X. Income inequality in today's China. Proc. Natl. Acad. Sci. (2014). doi:10.1073/pnas.1403158111 
18. Fan, J.-L. et al. Residential carbon emission evolutions in urban-rural divided China: An end-use and behavior analysis. Sustain. Dev. Energy Water Environ. Syst. 101, 323-332 (2013).

19. Zhao, X., Li, N. \& Ma, C. Residential energy consumption in urban China: A decomposition analysis. Energy Policy 41, 644-653 (2012).

20. Golley, J. \& Meng, X. Income inequality and carbon dioxide emissions: The case of Chinese urban households. Energy Econ. 34, 1864-1872 (2012).

21. Knight, J. Inequality in China An Overview. (The World Bank, 2013).

22. Liu, L.-C., Wu, G., Wang, J.-N. \& Wei, Y.-M. China's carbon emissions from urban and rural households during 1992-2007. J. Clean. Prod. 19, 1754-1762 (2011).

23. Minx, J. C. et al. A 'Carbonizing Dragon': China's Fast Growing $\mathrm{CO}_{2}$ Emissions Revisited. Environ. Sci. Technol. 45, 9144-9153 (2011).

24. Antal, M. \& Van Den Bergh, J. C. J. M. Green growth and climate change: conceptual and empirical considerations. Clim. Policy 16, 165-177 (2016).

25. Liu, Z. et al. Energy policy: A low-carbon road map for China. Nature 500, 143-145 (2013).

26. Zhang, X., Karplus, V. J., Qi, T., Zhang, D. \& He, J. Carbon emissions in China: How far can new efforts bend the curve? Energy Econ. 54, 388-395 (2016).

27. Akenji, L. Consumer scapegoatism and limits to green consumerism. J. Clean. Prod. 63, 13-23 (2014).

28. Fuchs, D. et al. Power: the missing element in sustainable consumption and absolute reductions research and action. J. Clean. Prod. (2015). doi:10.1016/j.jclepro.2015.02.006

29. Lorek, S. \& Spangenberg, J. H. Sustainable consumption within a sustainable economy - beyond green growth and green economies. J. Clean. Prod. 63, 33-44 (2014).

30. Groot, L. Carbon Lorenz curves. Resour. Energy Econ. 32, 45-64 (2010).

31. Teng, F., He, J., Pan, X. \& Zhang, C. Metric of Carbon Equity: Carbon Gini Index Based on Historical Cumulative Emission per Capita. Adv. Clim. Change Res. 2, 134-140 (2011). 
32. Duarte, R., Mainar, A. \& Sánchez-Chóliz, J. Social groups and CO2 emissions in Spanish households. Energy Policy 44, 441-450 (2012).

33. Baiocchi, G., Minx, J. \& Hubacek, K. The Impact of Social Factors and Consumer Behavior on Carbon Dioxide Emissions in the United Kingdom: A Regression Based on Input-Output and Geodemographic Consumer Segmentation Data. J. Ind. Ecol. 14, 50-72 (2010).

34. López, L. A., Arce, G., Morenate, M. \& Monsalve, F. Assessing the Inequality of Spanish Households through the Carbon Footprint: The 21st Century Great Recession Effect: Inequality and Carbon Footprint of Spain. J. Ind. Ecol. (2016). doi:10.1111/jiec.12466

35. Weber, C. L. \& Matthews, H. S. Quantifying the global and distributional aspects of American household carbon footprint. Ecol. Econ. 66, 379-391 (2008).

36. Kerkhof, A. C., Benders, R. M. J. \& Moll, H. C. Determinants of variation in household CO2 emissions between and within countries. Energy Policy 37, 1509-1517 (2009).

37. Xu, X., Han, L. \& Lv, X. Household carbon inequality in urban China, its sources and determinants. Ecol. Econ. 128, 77-86 (2016).

38. Liu, Z. et al. Reduced carbon emission estimates from fossil fuel combustion and cement production in China. Nature 524, 335-338 (2015).

39. Korsbakken, J. I., Peters, G. P. \& Andrew, R. M. Uncertainties around reductions in China's coal use and CO2 emissions. Nat. Clim. Change (2016). doi:10.1038/nclimate2963

40. Ottelin, J., Heinonen, J. \& Junnila, S. Greenhouse gas emissions from flying can offset the gain from reduced driving in dense urban areas. J. Transp. Geogr. 41, 1-9 (2014).

41. Girod, B., van Vuuren, D. P. \& Hertwich, E. G. Climate policy through changing consumption choices: Options and obstacles for reducing greenhouse gas emissions. Glob. Environ. Change 25, 5-15 (2014).

42. Girod, B., Vuuren, D. P. van \& Hertwich, E. G. Global climate targets and future consumption level: an evaluation of the required GHG intensity. Environ. Res. Lett. 8, 14016 (2013). 
43. Hofmann, J., Guan, D., Chalvatzis, K. \& Huo, H. Assessment of electrical vehicles as a successful driver for reducing CO2 emissions in China. Appl. Energy (2016).

doi:10.1016/j.apenergy.2016.06.042

44. Lorek, S. \& Spangenberg, J. H. Sustainable consumption within a sustainable economy - beyond green growth and green economies. Spec. Vol. Sustain. Prod. Consum. Livelihoods Glob. Reg. Res. Perspect. 63, 33-44 (2014).

45. Akenji, L. Consumer scapegoatism and limits to green consumerism. Spec. Vol. Sustain. Prod. Consum. Livelihoods Glob. Reg. Res. Perspect. 63, 13-23 (2014).

46. Creutzig, F., Baiocchi, G., Bierkandt, R., Pichler, P.-P. \& Seto, K. C. Global typology of urban energy use and potentials for an urbanization mitigation wedge. Proc. Natl. Acad. Sci. 112, 6283$6288(2015)$.

47. Ramaswami, A., Russell, A. G., Culligan, P. J., Sharma, K. R. \& Kumar, E. Meta-principles for developing smart, sustainable, and healthy cities. Science 352, 940-943 (2016).

48. Steinberger, J. K., Timmons Roberts, J., Peters, G. P. \& Baiocchi, G. Pathways of human development and carbon emissions embodied in trade. Nat. Clim. Change 2, 81-85 (2012).

49. Lamb, W. F. et al. Transitions in pathways of human development and carbon emissions. Environ. Res. Lett. 9, 14011 (2014).

50. Jorgenson, A. K. \& Givens, J. The Changing Effect of Economic Development on the ConsumptionBased Carbon Intensity of Well-Being, 1990-2008. PLOS ONE 10, e0123920 (2015). 


\section{Methods}

We quantify the household carbon footprints of 13 Chinese income groups ( 5 rural and 8 urban) for 2012 and 2007, using a detailed Chinese Environmentally Extended Input-Output model (IOT) and a global Multi-Regional Input-Output Model derived from the GTAP database (MRIO). The Chinese IOT has 135 sectors in producers prices ${ }^{52}$ and is extended by China's sectoral $\mathrm{CO}_{2}$ emissions from fossil fuel combustion and cement production, each corrected for the latest published estimates on coal carbon contents and energy use, which significantly altered the previously available official data ${ }^{39,53}$. Household consumption patterns for eight urban and five rural income groups are derived by disaggregating the urban and rural household final demand vectors in the Chinese IOTs with data on the respective consumption structures from the China Urban Lifestyle and Price Yearbooks ${ }^{54}$. These list average incomes and consumption patterns per income group, discerning 8 major classes of expenditure items and 58 sector specific items, which were mapped to the 135 sectors of the Chinese IOTs. In particular, i) we convert all 58 consumption categories into percentage to total per capita consumption; ii) we produce a concordance matrix to map the 58 sector specific items with 135 IOT sectors; iii) we derive 8 income group urban household consumption in 135 sectors IOT standard. We repeat the same process and utilise income-grouped household expenditure data provided from Chinese Rural Statistics to disaggregate the rural household average consumption into 5 income groups.

All international upstream emissions were calculated via an MRIO derived from the GTAP database for 2011 (140 countries x 57 sectors) and 2007 (129 countries x 57 sectors) $)^{55}$. International emissions of fossil fuels and cement production by sector are derived from the GTAP emissions database and corrected with the latest revised Chinese emissions statistics ${ }^{39,53}$. This is important because households directly consume imports and the Chinese economy requires imported intermediate inputs to produce domestic final output, which constitutes an important international inter-industry feedback ${ }^{56}$. The limitations of this study are firstly, that non-CO2 greenhouse gas emissions are not included due to lack of available sector level data for China. Secondly, Input-Output Analysis generally only considers the annual emissions (flows) within the same year, which means that cumulative emissions (stocks) required to build existing infrastructure and buildings are not accounted for - which can be seen as an issue especially for housing related footprints, which are currently driven by electricity, natural gas and household appliances. More generally this means that the consumption of capital is currently not endogenized in our model, as this is an ongoing issue for $\mathrm{IO}$ analysis in general (see $\mathrm{SI}$ for a longer discussion on the methodological limitations). The 
concordances between the MRIO and the Chinese IOT are derived from the GTAP documentation (see SI).

Carbon footprint results for 135 Chinese and 57 international sectors were aggregated to five major categories of consumption: housing, mobility, food, goods and services (SI). Emissions from direct household energy use of coal, natural gas and electricity are allocated to the category housing, oil emissions to mobility. Due to data constraints in the GTAP-MRIO direct energy use for non-Chinese households cannot be completely allocated and was kept separate (see Figure 1 and SI).

\section{Quantifying Inequality via Carbon-Footprint Ginis}

The consumption-based carbon-footprint-Gini coefficient presented herein is based on the wellknown Gini-coefficient, which is derived from Lorenz curves, initially proposed by Lorenz in 1907 and widely used to measure inequality ${ }^{7,10,17,30,31}$. The original Lorenz curve plots population shares against income shares, where the area below that curve is defined as Gini coefficient, ranging from 0 to 1 . A straight $45^{\circ}$ line in the Lorenz curves would indicate perfect equality, similarly a Gini coefficient of 0 indicates perfect equality and 1 perfect inequality. In this paper, we present a consumption-based carbon-footprint-Gini index across 13 income groups and their carbon footprints. Let's define the following variables for group $\mathrm{n}: C_{i}^{n}$ is the carbon footprint of group $n$ for product $i, P_{o p}{ }^{n}$ is the population size of income group $n$, and $p^{n}=\frac{P o p^{n}}{\sum_{m} P o p^{n}}$ is the population share of group $n$.

$C^{n}=\frac{C_{i}^{n}}{\sum_{m} C_{i}^{n}}$ is then the share in total household carbon footprint of group $n$ for product $i$. Define the area between the actual allocation curve and perfect equal allocation curve as $X$, the area below the actual allocation curve as $\mathrm{Y}$. Then the Gini index is defined as $\mathrm{X} /(\mathrm{X}+\mathrm{Y})$. Table $\mathrm{S} 3$ provides the population and carbon footprints of each group in 2007 and 2012.

\section{Estimation of demand growth and catch-up scenarios}

For the simple expenditure redistribution and lifestyle catch-up scenarios reported in the main manuscript, we utilized the headline findings on expenditure/cap, total carbon footprints and carbon-footprint elasticities (Table 1; main manuscript).

For the redistribution scenario we calculated the average per capita household expenditure $(1,762.26$ US\$ MER) for all Chinese households, which we then redistributed from each income group. Then we used the CF-elasticity of each income group to calculate the changes in the carbon footprint of each group. 
For the lifestyle catch-up scenarios we used two reference points. Firstly, the average expenditure per capita from the urban rich groups (5,768 US\$) and secondly the average expenditure per capita of the three urban middle-class groups (2,406 US\$). For all income groups below these two reference points we used each income groups' CF-elasticity to calculate the additional carbon footprints resulting from such a catch-up of expenditures. For both scenarios we also used the CF-elasticities of the two catch-up reference points for all additional expenditures, which yields only marginally lower additional total household carbon footprints. In the main manuscript we report numbers based on each groups' own CF-elasticity.

\section{Literature}

51. NBS. Input-Output Table of China, 2012 and 2007. (National Bureau of Statistics, Statistical Press, 2015).

52. NBS. Energy Statistical Yearbook of China fourth revision; 2012 and 2007. (Statistical Press, 2016).

53. NBS. China Urban Life and Price Yearbook 2011 and 2007. (National Bureau of Statistics, Statistical Press, 2012).

54. Narayanan, B., Aguiar, A. \& McDougall, R. Global Trade, Assistance, and Production: The GTAP 9 Data Base. (Center for Global Trade Analysis, Purdue University, 2015).

55. Su, B. \& Ang, B. W. Multi-region input-output analysis of $\mathrm{CO} 2$ emissions embodied in trade: The feedback effects. Ecol. Econ. 71, 42-53 (2011). 